\title{
Application of Daubechies Wavelet Transformation for Noise Rain Reduction on the Video
}

\author{
Siti Khotijah and Dwi Ratna Sulistyaningrum
}

\begin{abstract}
Currently, the use of digital video in the field of computer science is increasingly widespread, such as the process of tracking objects, the calculation of the number of vehicles, the classification of vehicle types, vehicle speed estimation and so forth. The process of taking digital video is often influenced by bad weather, such rain. Rain in digital video is considered noise because it is able to block objects being observed. Therefore, a rainfall noise reduction process is required in the video. In this study, the reduction of rain noise in digital video is using Daubechies wavelet transformation through several processes, namely: wavelet decomposition, fusion process, thresholding process and reconstruction process. The threshold value used in the thresholding process is VishuShrink, BayesShrink, and NormalShrink. The result of the implementation and noise reduction test show that Daubechies db2 level 3 filter gives the result with the biggest PSNR value. As for the type of threshold that provides optimal results is VishuShrink.
\end{abstract}

Index Terms-Daubechies Wavelet Transformation, fusion, VishuShrink, BayesShrink, NormalShrink.

\section{INTRODUCTION}

C URRENTLY, the use of digital cameras is not only limited to shooting but also on digital video recording. In addition to indoor use, digital video is also often used outdoors such as traffic control, vehicle speed estimation, vehicle type classification, mobile vehicle number calculation, and so on. However, bad weather often affects the resulting digital video, one of which is digital video capture in the rain so that the observed object becomes obscure because it is blocked by the rain. Rain in digital video is considered noise because it is able to block objects being observed. Therefore, a digital image processing application is required to reduce or even eliminate the presence of rain noise in the video.

In previous research, many researchers have conducted rainwater noise reduction research on video. As has been done by Garg and Nayar [1] using Robust method. Then, Zhang [2] use K-Means cluster method and frame difference. Nikhil Gupta [3] also conducted a study to reduce noise in the form of Gaussian noise by using wavelet transform and the result is significant. While Chen Zhen [4] uses a multilevel wavelet decomposition method and states that the noise reduction results are better than the K-Means Cluster method and the frame difference method.

In this study, the reduction of rain noise on video is conducted by applying wavelet and wavelet fusion transformation.

Manuscript received February 2, 2018; accepted July 27, 2018.

The authors are with the Department of Mathematics, Faculty of Mathematics, Computing, and Data Sciences, Institut Teknologi Sepuluh Nopember, Surabaya, Indonesia. E-mails: ija.st29@gmail.com, dwiratna@matematika.its.ac.id
Wavelets used in wavelet fusion are Daubechies wavelets coupled with a thresholding process to reduce rain noise. The wavelet transform is used to obtain rain detail on the video image, while wavelet fusion is used to clarify the rain noise that will be reduced through the thresholding process.

\section{Procedure of Rain Reduction on Video Based \\ WAVELET TRANSFORMATION AND WAVELET FUSION}

\section{A. Wavelet Decomposition}

Based on [5], wavelet transformation can decompose image into eeg sub-bands with different resolution, frequency characteristics and directional characteristics. With the inspiration of image decomposition and image reconstruction, we obtained a result of the division of image into a low-frequency and three high-frequency as shown in Fig. 1.

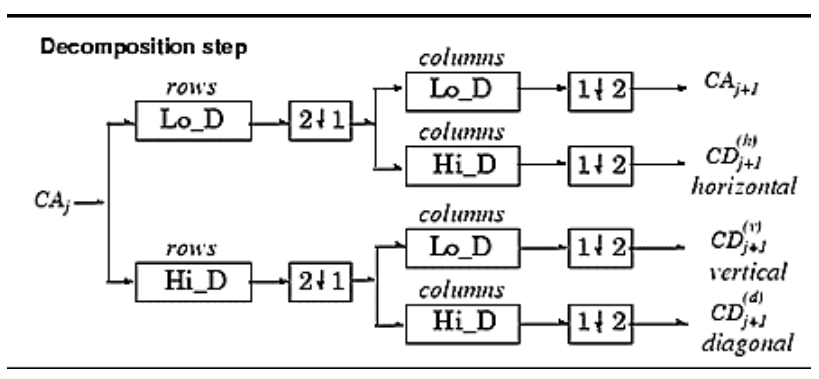

Fig. 1. One level of 2-D DWT image decomposition.

Where $C_{A j+1}$ is the low-frequency component of image $C_{A j}$, $C D_{j+1}^{(h)}$ is high-frequency component in horizontal direction, $C D_{j+1}^{(v)}$ is the high-frequency component in vertical direction, $C D_{j+1}^{(d)}$ is the high-frequency component in diagonal direction.

Figure 1 shows that $C_{A j+1}$ is a part of the coefficient obtained through the process of low pass filter on the rows continued by a low pass filter on the column, image of this section is similar and more subtle than $C_{A j}$ image. So, it is called the approximation component. $C D_{j+1}^{(h)}$ is a part of the coefficient obtained through the process of low pass filter on the rows continued by a high pass filter on the column, $C D_{j+1}^{(v)}$ is a part of the coefficient obtained through the process of high pass filter on the rows continued by a low pass filter on the column, and $C D_{j+1}^{(d)}$ is a part of the coefficient obtained through the process of high pass filter on the rows continued by a high pass filter on the column.

\section{B. Wavelet Fusion}

Wavelet fusion is a combination of two images obtained of wavelet transformation. Based on [6], the wavelet transform 
method is very well used for fusion methods because wavelet transforms can divide images into high and low frequencies at the same resolution as shown in Fig. 2.

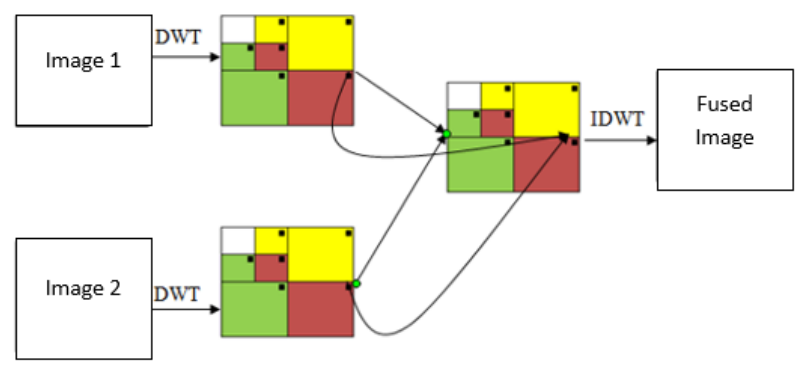

Fig. 2. Block diagram of generic fusion schemes

In this research, wavelet fusion is conducted to combine two frames with the aim that the rain noise becomes clearer as shown in Fig. 4. Based on [7], the wavelet fusion rule is made by measuring activity-level using a window-based method in the form of spatial-frequency method. The spatial-frequency method is calculated based on the local gradient value and the local energy of each subband [6]. The fusion rules are based on the parameters resulting from the multiplication of the local gradient and the local energy of each component of the decomposition result. To calculate local gradient and local energy values using (1) and (2).

$$
\begin{aligned}
G & =\frac{1}{M N} \sum_{i=1}^{M} \sum_{j=1}^{N} \sqrt{\Delta x f(i, j)^{2}-\Delta y f(i, j)^{2}} \\
E & =\frac{1}{M N} \sum_{i=1}^{M} \sum_{j=1}^{N} f(i, j)^{2}
\end{aligned}
$$

where $G$ is the local gradient, $E$ is the local energy $1, \Delta x f(i, j)$ is the gradient of point $(i, j)$ on horizontal direction, $\Delta y f(i, j)$ is the gradient of point $(i, j)$ on vertical direction, and $M, N$ is the dimension of image.

\section{Thresholding}

On the process of thresholding, the detailed coefficient of the decomposition at each decomposition level that has passed the fusion rule is compared with a threshold-t value with the soft-thresholding and hard-thresholding functions shown in (3) and (4):

$$
\begin{aligned}
& \hat{d}^{\lambda}=T_{s}\left(d^{\lambda}, t\right)=\left\{\begin{aligned}
d^{\lambda}-t, & d^{\lambda} \geq t, \\
0, & \left|d^{\lambda}\right|<t, \\
d^{\lambda}+t, & d^{\lambda}<-t,
\end{aligned}\right. \\
& \hat{d}^{\lambda}=T_{s}\left(d^{\lambda}, t\right)=\left\{\begin{array}{rr}
d^{\lambda}, & \left|d^{\lambda}\right| \geq t, \\
0, & \left|d^{\lambda}\right|<t,
\end{array}\right.
\end{aligned}
$$

threshold-t values are obtained based on [8], [9], [10], i.e. BayesShrink, VishuShrink and NormalShrink.

\section{Wavelet Reconstruction}

The reconstruction of the wavelet is inverse of the wavelet decomposition by combining an approximation coefficient and the three detailed coefficients that has been passed fusion rule and thresholding process. Process of wavelet reconstruction is shown in Fig. 3.

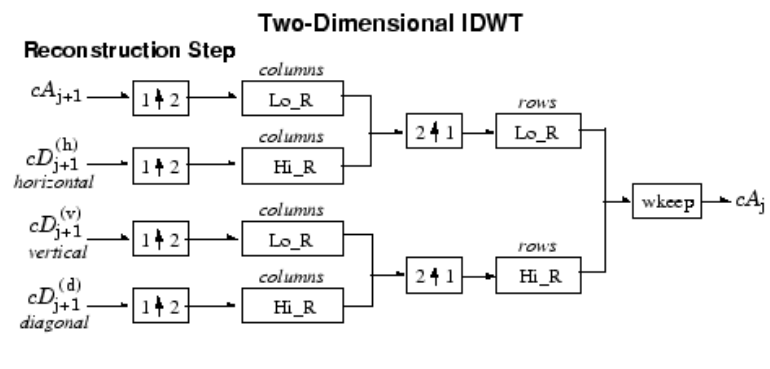

Fig. 3. One level of 2-D IDWT image reconstruction.

\section{E. Peak Signal to Noise Ratio (PSNR)}

PSNR in this study was used to compare each frame of the video of the reduction with each frame on the video before it was exposed to the rain noise. Based on [11], it is calculated using (5):

$$
P S N R=10 \log _{10} \frac{\left(2^{M}-1\right)^{2}}{M S E}
$$

where $\left(2^{M}-1\right)^{2}$ represents the maximum pixel value for the $M$ bit of the video frame. $M S E$ is the mean square error calculated using equation (6):

$$
M S E=\frac{1}{M N}\left[I(x, y)-I^{\prime}(x, y)\right]^{2}
$$

where $M, N$ is the image dimension. $I(x, y)$ is the pixel value of the video frame before it rains. While $I^{\prime}(x, y)$ is the video frame pixel value after the noise reduction process.

\section{EXPERIMENTS AND RESULTS}

\section{A. Experimental Data}

The experiments are conducted on rain video with extension .avi with a speed of $25 \mathrm{fps}$ with a resolution of $768 \times 576$, rain with characteristics $10000 / \mathrm{sec}$, rain size $0.00004 \mathrm{~mm}$, dept 5000 , speed 3000 . This experiment is conducted by applying wavelet transformation Daubechies db2, db4 db6 and db8 with 3rd decomposition level. Type threshold uses BayesShrink, VishuShrink and NormalShrink.

\section{B. Results}

As mentioned before, the first step taken to conduct a rainwater noise reduction test on a video is to select a video to be tested. Next, we select the Daubechies wavelet type to decompose the frame, aiming to separate between rain detail and other component details according to the level of decomposition level. The next step is using the wavelet fusion to make the rain more clear. In this research, wavelet fusion uses 2 frames close together i.e. frame 1 and frame 2, frame 2 and so on up to $n$-th frame. The results of the wavelet fusion process are shown in Fig. 5.

The final step is to select the type of threshold to reduce the rain noise. The result will be reconstructed and rendered back into a video that has been reduced to rain, as shown in Fig. 6.

The results of rainfall noise reduction test based on decomposition level, threshold type and computation time are shown in Table I, Table II and Table III. 


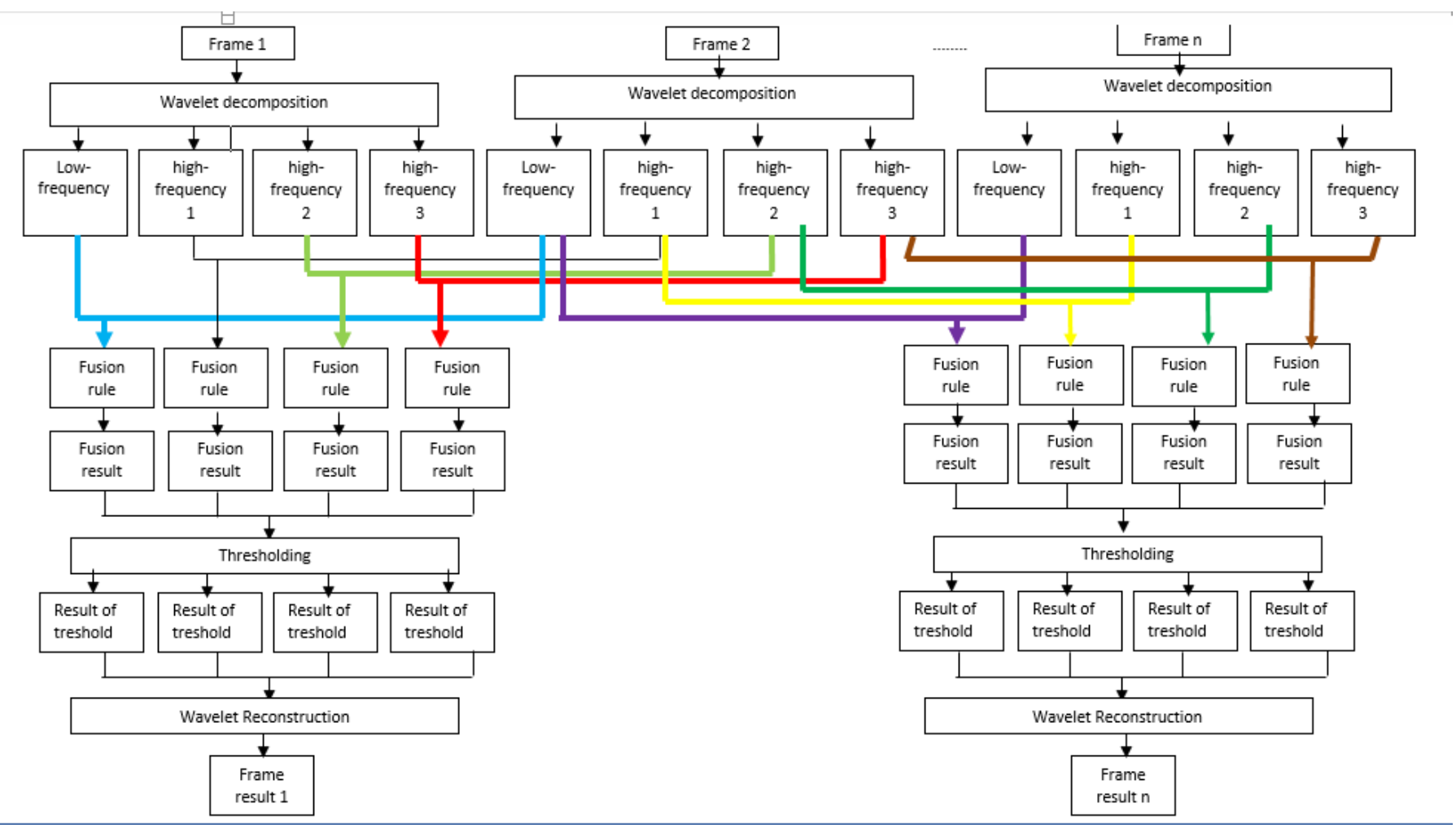

Fig. 4. Flowchart process noise reduction on video based wavelet transformation and wavelet fusion.
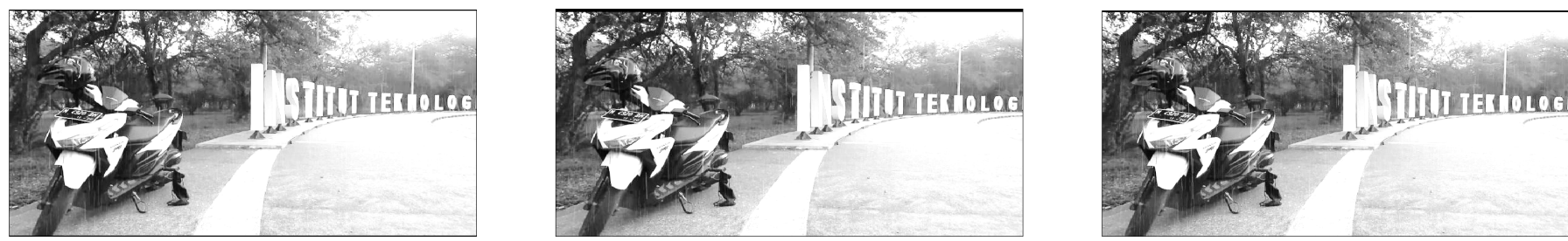

Fig. 5. Result of fusion wavelet process.
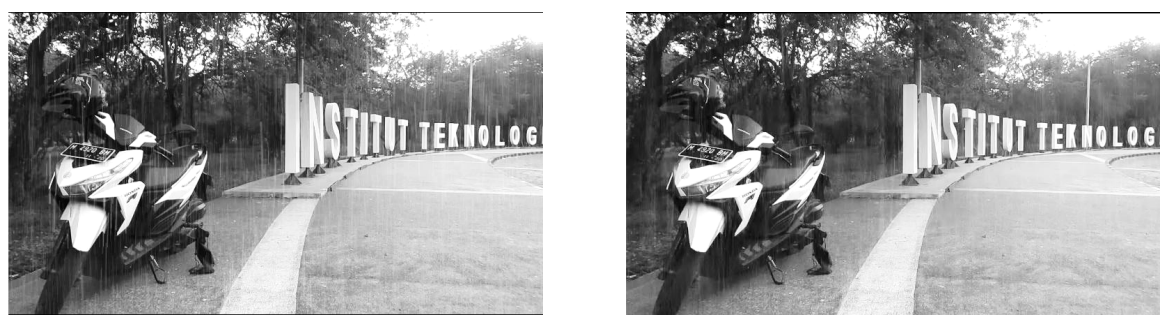

Fig. 6. The result of rain noise reduction. The left part is the frame before reduction and the right part is the frame after reduction.

Analysis of wavelet transform performance on wavelet fusion with different threshold type based on test result in Table I, Table II and Table III is as follows:

- Daubechies wavelet transformation db2 is good for level 3 with PSNR ratio of $32.0888 \mathrm{~dB}$ with computation time 32.0390 seconds.

- The type of threshold that is good to use is VishuShrink.

\section{CONCLUSIONS}

Based on the results of the experiments, it can be concluded that Daubechies wavelet transformation in wavelet fusion with
vishuShrink threshold type is good for reduction rain noise on video .avi with speed $25 \mathrm{fps}$ with resolution $768 \times 576$, rain with characteristic 10.000 / seconds, rain size $0.00004 \mathrm{~mm}$, dept 5000, speed 3000 .

\section{REFERENCES}

[1] K. Garg and S. K. Nayar, "Detection and removal of rain from videos," in Computer Vision and Pattern Recognition, 2004. CVPR 2004. Proceedings of the 2004 IEEE Computer Society Conference on, vol. 1, 2004, pp. I-I.

[2] X. Zhang, H. Li, Y. Qi, W. K. Leow, and T. K. Ng, "Rain removal in video by combining temporal and chromatic properties," in IEEE International Conference on Multimedia and Expo, 2006, pp. 461-464. 
TABLE I

COMPARISON OF PSNR OF BAYESSHRINK VALUE AND PROCESSING TIME.

\begin{tabular}{|c|c|c|c|c|c|c|}
\hline No & Wavelet & Level & $\begin{array}{l}\text { PSNR } \\
\text { BayesShrink } \\
\text { (dB) }\end{array}$ & $\begin{array}{l}\text { Processing } \\
\text { time }(\mathrm{sec})\end{array}$ & $\begin{array}{l}\text { increase } \\
\text { in PSNR }\end{array}$ & $\begin{array}{l}\text { increase } \\
\text { in pro- } \\
\text { cessing } \\
\text { time } \\
(\mathrm{sec})\end{array}$ \\
\hline 1 & $\mathrm{Db} 2$ & $\begin{array}{l}1 \\
2 \\
3\end{array}$ & $\begin{array}{l}30.5508 \\
31.0197 \\
31.3753\end{array}$ & $\begin{array}{l}21.4246 \\
26.5174 \\
30.8372\end{array}$ & $\begin{array}{l}0 \\
0.4689 \\
0.3556\end{array}$ & $\begin{array}{l}0 \\
5.0928 \\
4.3198\end{array}$ \\
\hline 2 & $\mathrm{Db} 4$ & $\begin{array}{l}1 \\
2 \\
3\end{array}$ & $\begin{array}{l}30.6406 \\
31.1038 \\
31.4754\end{array}$ & $\begin{array}{l}21.634 \\
27.1085 \\
33.7299\end{array}$ & $\begin{array}{l}0 \\
0.4632 \\
0.3716\end{array}$ & $\begin{array}{l}0 \\
5.4745 \\
6.6214\end{array}$ \\
\hline 3 & Db6 & $\begin{array}{l}1 \\
2 \\
3\end{array}$ & $\begin{array}{l}30.667 \\
31.14 \\
31.4953\end{array}$ & $\begin{array}{l}23.2527 \\
27.9771 \\
32.332\end{array}$ & $\begin{array}{l}0 \\
0.473 \\
0.3553\end{array}$ & $\begin{array}{l}0 \\
4.7244 \\
4.3549\end{array}$ \\
\hline 4 & Db8 & $\begin{array}{l}1 \\
2\end{array}$ & $\begin{array}{l}30.6744 \\
31.1342 \\
\end{array}$ & $\begin{array}{l}22.5959 \\
28.6292 \\
\end{array}$ & $\begin{array}{l}0 \\
0.4598\end{array}$ & $\begin{array}{l}0 \\
6.0333\end{array}$ \\
\hline
\end{tabular}

TABLE II

COMPARISON OF PSNR OF VISHUSHRINK VALUE AND PROCESSING TIME.

\begin{tabular}{|l|l|l|l|l|l|l|}
\hline No & Wavelet & Level & $\begin{array}{l}\text { PSNR } \\
\text { VishuShrink } \\
(\mathrm{dB})\end{array}$ & $\begin{array}{l}\text { Processing } \\
\text { time (sec) }\end{array}$ & $\begin{array}{l}\text { increase } \\
\text { in PSNR }\end{array}$ & $\begin{array}{l}\text { increase } \\
\text { in pro- } \\
\text { cessing } \\
\text { time } \\
\text { (sec) }\end{array}$ \\
\hline \multirow{2}{*}{1} & $\mathrm{Db} 2$ & 1 & 31.1415 & 21.9082 & 0 & 0 \\
& & 3 & 31.6746 & 27.5886 & 0.5331 & 5.6804 \\
\hline \multirow{2}{*}{2} & \multirow{2}{*}{$\mathrm{Db} 4$} & 1 & 32.0888 & 32.039 & 0.4142 & 4.4504 \\
\hline & & 3 & 31.6574 & 23.2612 & 0 & 0 \\
\hline 3 & \multirow{2}{*}{$\mathrm{Db6}$} & 1 & 32.0801 & 32.1383 & 0.5154 & 5.4771 \\
& & 3 & 31.6539 & 22.8609 & 0.4227 & 3.3972 \\
\hline \multirow{2}{*}{4} & \multirow{2}{*}{$\mathrm{Db} 8$} & 1 & 32.0552 & 33.1531 & 0.5239 & 0 \\
& & 3 & 31.6374 & 23.378 & 0.4013 & 4.5114 \\
\hline
\end{tabular}

TABLE III

COMPARISON OF PSNR OF NORMALSHRINK VALUE AND PROCESSING TIME.

\begin{tabular}{|c|c|c|c|c|c|c|}
\hline No & Wavelet & Level & $\begin{array}{l}\text { PSNR } \\
\text { Normal- } \\
\text { Shrink } \\
\text { (dB) }\end{array}$ & $\begin{array}{l}\text { Processing } \\
\text { time }(\mathrm{sec})\end{array}$ & $\begin{array}{l}\text { increase } \\
\text { in PSNR }\end{array}$ & $\begin{array}{l}\text { increase } \\
\text { in pro- } \\
\text { cessing } \\
\text { time } \\
(\mathrm{sec})\end{array}$ \\
\hline \multirow{3}{*}{1} & \multirow{3}{*}{$\mathrm{Db} 2$} & 1 & 30.5515 & 21.11 & 0 & 0 \\
\hline & & 2 & 31.0192 & 26.6279 & 0.4677 & 5.5179 \\
\hline & & 3 & 31.3743 & 30.9678 & 0.3551 & 4.3399 \\
\hline \multirow{3}{*}{2} & \multirow{3}{*}{$\mathrm{Db} 4$} & 1 & 30.641 & 21.6687 & 0 & 0 \\
\hline & & 2 & 31.103 & 27.1454 & 0.462 & 5.4767 \\
\hline & & 3 & 31.4714 & 31.4622 & 0.3684 & 4.3168 \\
\hline \multirow{3}{*}{3} & \multirow{3}{*}{ Db6 } & 1 & 30.6674 & 22.1931 & 0 & 0 \\
\hline & & 2 & 31.139 & 27.6346 & 0.4716 & 5.4415 \\
\hline & & 3 & 31.4937 & 32.4054 & 0.3547 & 4.7708 \\
\hline \multirow{3}{*}{4} & \multirow{3}{*}{ Db8 } & 1 & 30.6748 & 22.4686 & 0 & 0 \\
\hline & & 2 & 31.1331 & 28.5022 & 0.4583 & 6.0336 \\
\hline & & 3 & 31.4851 & 33.0122 & 0.352 & 4.5100 \\
\hline
\end{tabular}

[3] N. Gupta, "Video modeling and noise reduction in the wavelet domain," Ph.D. dissertation, Concordia University, 2011.

[4] C. Zhen and S. Jihong, "A new algorithm of rain (snow) removal in video." Journal of Multimedia, vol. 8, no. 2, 2013.

[5] S. G. Mallat, "A theory for multiresolution signal decomposition: the wavelet representation," IEEE transactions on pattern analysis and machine intelligence, vol. 11, no. 7, pp. 674-693, 1989.

[6] G. Pajares and J. M. De La Cruz, "A wavelet-based image fusion tutorial," Pattern recognition, vol. 37, no. 9, pp. 1855-1872, 2004.

[7] Z. Zhang and R. S. Blum, "A categorization of multiscaledecomposition-based image fusion schemes with a performance study for a digital camera application," Proceedings of the IEEE, vol. 87, no. 8 , pp. 1315-1326, 1999.

[8] D. L. Donoho and J. M. Johnstone, "Ideal spatial adaptation by wavelet shrinkage," biometrika, vol. 81, no. 3, pp. 425-455, 1994.

[9] S. G. Chang, B. Yu, and M. Vetterli, "Adaptive wavelet thresholding for image denoising and compression," IEEE transactions on image processing, vol. 9, no. 9, pp. 1532-1546, 2000.

[10] M. Kaur, K. Sharma, and N. Dhillon, "Image denoising using wavelet thresholding," International Journal of Engineering and Computer Science, vol. 2, no. 10, 2013.

[11] M. Vranjes, S. Rimac-Drlje, and K. Grgic, "Locally averaged psnr as a simple objective video quality metric," in 50th International Symposium ELMAR, vol. 1, 2008, pp. 17-20. 